\title{
Peningkatan Pengetahuan Faktor-Faktor yang Memengaruhi Perilaku Seks dalam Upaya Cegah Seks Pranikah pada Siswa-Siswi SMPN 77 dan SMAN 77 Jakarta Pusat
}

\author{
Tri Panjiasih Susmiarsih ${ }^{1^{*}}$, Himmi Marsiati ${ }^{2}$, Susi Endrini $^{2}$ \\ ${ }^{1}$ Bagian BiologiFK Universitas YARSI \\ Jl. Letjen Suprapto Cempaka Putih Jakarta Pusat 10510 \\ ${ }^{2}$ Bagian BiokimiaFK Universitas YARSI \\ Jl. Letjen Suprapto Cempaka Putih Jakarta Pusat 10510 \\ "tri.panjiasih@yarsi.ac.id
}

Submisi: 23 Maret 2018; Penerimaan: 19 Maret 2019

\section{Kata kunci:}

kesehatan reproduksi; perilaku seks; seks pranikah
Keywords:prema rital sex;reproductive health; sexual behavior
ABSTRAK Perilaku seks pranikah merupakan permasalahan dan fenomena sosial yang semakin lazim dijumpai dalam masyarakat. Masalah perilaku seks pranikah pada usia muda harus menjadi perhatian utama untuk mengurangi tingkat kehamilan yang tidak diinginkan, penyakit menular seksual, penyebab putus sekolah, aborsi, dan kematian. Salah satu upaya mencegah perilaku seks pranikah pada siswa di sekolah adalah dengan metode pembekalan pengetahuan tentang perilaku seks, kesehatan reproduksi, pemahaman agama, dan hukum pernikahan dini. Indikator evaluasi menggunakan data kuesioner pre-testdan posttest yang dianalisis dengan uji $\mathrm{t}$ berpasangan dan uji regresi. Hasil analisis membuktikan bahwa setelah penyuluhan, pengetahuan para siswa SMP tentang perilaku seks, kesehatan reproduksi, dan pengetahuan agama meningkat secara bermakna $(\mathrm{p}<0.05)$. Adapun pada siswa-siswa SMA, pengetahuan agama dan hukum perkawinan dini juga meningkat secara bermakna.

ABSTRACT The premarital sex behavior is a problem and social phenomenon that is increasingly prevalent in society. At a young age, the premarital sex should be a major concern to reduce pregnancy rates unintended, sexually transmitted diseases, school drop out, abortion and even a death. One effort to prevent the premarital sex behavior for students in schools with methods of providing knowledge about sexual behavior, reproductive health, an understanding of religious and the early marriage law. Evaluation of indicators usingpre test and post test data that are analyzed with paired t and regression test. The results show that after counseling, the knowledge of junior high school students about sexual behavior, reproductive health and religious knowledge increased significantly ( $p$ $<0.05$ ), while high school students of religious knowledge and early marriage law increased significantly. 


\section{PENDAHULUAN}

Perilaku seks pranikah merupakan permasalahan dan fenomena sosial yang semakin lazim dijumpai dalam masyarakat. Perilaku seks bebas tidak hanya didominasi oleh negara maju, namun juga banyak ditemui di negara berkembang. Hasil survei di beberapa negara berkembang menunjukkan bahwa $46 \%$ remaja putri (14-17 tahun) dan $66.2 \%$ remaja putra di Liberia sudah bersenggama serta38\% remaja putri dan $57.3 \%$ remaja putra (15-19 tahun) di Nigeria sudah bersenggama (Sarwono, 2011). Indonesia sebagai negara berkembang tampaknya harus bercermin dari data survei tersebut.

Transisi kehidupan terpenting dari masa remaja adalah masa pubertas, yakni masa terjadinnya perkembangan biologis yang bermakna serta perkembangan sosial dan emosional. Perkembangan biologis yang bermakna ini ditandai oleh perkembangan alat dan perilaku reproduksi.Pada masa remaja, perkembanganseksualitas diawali oleh perubahan fisik, hormonal, sosial, dan psikologis sehingga muncul rasa ingin tahu yang besar dan keinginan untuk coba-coba akibat perubahan tersebut.Hasil survei BKKBN pada 2011 menunjukkan bahwa 71\%remaja di Indonesia mengaku pacaran; 88\%berpegangan tangan, 32\%mencium bibir, 11\% meraba atau merangsang, dan $2 \%$ remaja putri serta $5 \%$ remaja putra telah melakukanhubungan seksual. Hubungan seksual yang dilakukan bersama pacar sebesar 90\% dan $10 \%$ dilakukan bersama teman atau pekerja seks komersial.

Hasil survei BKKBN juga menunjukkan bahwa hubungan seksual terbanyak dilakukan oleh remaja usia20-24tahun, yaknisebesar9,9 persen dan 2,7 persen dilakukan oleh remaja usia15-19 tahun. Terkait hal tersebut, remaja di Indonesia memperoleh informasi tentang seks pranikah melalui media massa, mediacetak, TVdanradio,webonline dan jejaring social lainnya, serta dari teman sebaya yang pernah melakukan hubungan seks pranikah (BKKBN,2011) .Menurutdata KPAI dan Kemenkes, sekitar 62,7\% remaja di Indonesia telah melakukan hubungan seks di luar nikah. Data yang berumber dari survei yang dilakukan oleh Komite Perlindungan Anak Indonesia (KPAI), dan Kementrian Kesehatan, (Kemenkes) pada Oktober 2013 menunjukkan bahwa 94.270 perempuan yang mengalami hamil di luar nikah, 20\%adalah kelompok usia remaja dan $21 \%$ terinfeksi HIV yang $30 \%$ dari penderitanya berusia remaja.Perilaku seks pranikah pada usia remaja harus menjadi perhatian utama untuk mengurangi tingkat kehamilan yang tidak diinginkan, penyakit menular seksual, penyebab putus sekolah, aborsi, dankematian.

Perilaku seks pranikah merupakan aktivitas seksual yang dilakukan oleh individu dengan orang lain sebelum menikah (Djamba, 2013). Penyebaran informasi mengenai bahaya perilaku seks pranikah bagi kesehatan reproduksi remaja masih sangat dibutuhkan. Banyak faktor yang memengaruhi perilaku seksual pranikah, antara lain hubungan antara orang tua dengan remaja, pergaulan dengan teman sebaya, religius dan paparan media pornografi, serta nilai dan norma-norma yang berlaku di masyarakat (Soetjiningsih, 2012; Suryoputro et al., 2006). Selain itu, faktor yang juga memengaruhi perilaku seksual pranikah pada remajaadalah tingkat pengetahuan. Terdapat hubungan yang signifikan antara tingkat pengetahuan dengan perilaku seksual pranikah, yakni siswa yang memiliki pengetahuan yang baik dapat memahami perilaku seksual dengan baik pula, sedangkan siswa yang memiliki tingkat pengetahuan buruk memiliki pemahaman buruk juga tentang perilaku seksual (Darmasilh, 2011). 


\section{MASALAH}

Persentase remaja yang melakukan seks pranikah, hamil muda, dan menjadi ibu mudayang tinggi mendorongpemerintah untuk mengeluarkan UU RI No. 52 Tahun 2009 yang memuat kebijakan pembangunan keluarga melalui pembinaan ketahanan dan kesejahteraan keluarga serta peningkatan kualitas remaja dengan pemberian akses informasi, pendidikan, konseling, dan pelayanan tentang kehidupan berkeluarga. Perilaku seksual remaja diIndonesiasaat inisudahsangat mengkhawatirkan, termasuk di Jakarta. Oleh karena itu, upaya cegah perilaku seks bebas di kalangan remaja sekolah, khususnya siswa sekolah menengah pertama dan atas perlu ditingkatkan, yakni melalui akses informasi dengan cara pembekalan pengetahuan tentang beberapa faktor yang memengaruhi seks pranikah, antara lain perilaku seks, kesehatan reproduksi, pengetahuan agama tentang seks pranikah, dan hukum perkawinan dini.

\section{METODE}

\subsection{Metode Kegiatan}

Rancangan kegiatan ini adalah cross sectional dengan mendeskripsikan secara kuantitatif peningkatan pengetahuan faktor kesehatan reproduksi, agama, hukumpernikahan dini, dan perilaku seksual pranikah pada remaja SMP dan SMA.

\subsection{Lokasi dan Waktu Kegiatan}

Kegiatan dilaksanakan di SMPN dan SMAN 77 Cempaka Putih, Jakarta Pusat sejakDesember 2017 hingga Januari 2018.

\subsection{Teknilk Pengambilan dan Analisis Data}

Jumlah sampel dalam kegiatan ini adalah 57 siswa SMPN 77 dan 58siswa SMAN 77 yang aktif mengikuti unit-unit kegiatan siswa, hadir saat pembagian kuesioner, bersedia menjadi responden, dan mengikuti kegiatan pembekalan. Pengumpulan data dilakukan dengan kuesionerpre-test sebelum pembekalan dan kuesionerpost-test setelah pembekalan. Soal-soal dalam kuesioner bermodel benar atau salah dengan penilaian angka 1 untuk jawaban benar dan angka 0 untuk jawaban salah sehingga total nilai berjumlah 10 .

Setelah dilakukan pre-test, subjek kegiatan kemudian diberi pembelajaran atau pembekalan pengetahuan tentang perilaku seks, kesehatan reproduksi, pengetahuan agama, dan pengetahuan hukum pernikahan dini untuk mencegah seks pranikah. Pembekalan dilakukan oleh pemateri yang kompetendi bidangnya, yakni dosen-dosen dari Universitas YARSI yang meliputi dosen bagian anatomi fakultas kedokteran, dosen bagian agama, dosen fakultas psikologi, dan dosen fakultas kedokteran. Selama pembekalan, peserta berdiskusi dengan sangat antusias. Mereka diharapkan akan mampu menjadi kader untuk melakukan transfer edukasi dan secara rutin melakukan upaya cegah seks pranikah tidak hanya untuk diri sendiri, namun juga untuk teman sebayanya.Data yang diperoleh dari kuesioner selanjutnya dianalisis dengan uji t berpasangan dan uji korelasi regresi.

\section{HASIL DAN PEMBAHASAN}

Hasil pengukuran tingkat pengetahuan siswa-siswi SMPN 77 dan SMAN 77 yang dilakukan pada awal pertemuan menunjukkan masih rendahnya tingkat pengetahuan siswa 
tentang perilaku seksual, kesehatan reproduksi, pemahaman agama, dan pemahaman hukum pernikahan dini. Berdasarkan hasil pre-test dan post-test diketahui bahwa nilai rata-rata pengetahuan siswa-siswi SMPN 77 lebih rendah daripada siswa-siswi SMAN 77 (Tabel 4.1).

Tabel 4.1Nilai Pengetahuan Siswa-Siswi SMPN 77 dan SMAN 77

\begin{tabular}{lcccc}
\hline \multirow{2}{*}{ Pengetahuan } & \multicolumn{2}{c}{ SMPN 77 } & \multicolumn{2}{c}{ SMAN 77 } \\
\cline { 2 - 5 } & Pre-Test & Post-Test & Pre-Test & Post-Test \\
\hline Kesehatan Reproduksi & 66,9 & 82,61 & 83,33 & 88,51 \\
Perilaku Seksual Pranikah & 72,76 & 82,96 & 81,11 & 87,37 \\
Agama & 77,93 & 88,89 & 78,15 & 91,23 \\
Hukum Pernikahan Dini & 70,69 & 77,31 & 83,79 & 91,23 \\
\hline
\end{tabular}

Sumber : Data Primer diolah (2018)

Tingkat pengetahuan siswa-siswi SMP N 77 juga lebih rendah daripada siswa-siswi SMA N 77 (Tabel 4.2). Hasil ini sejalan dengan konsep yang dikemukakan oleh Notoadmodjo (2012) bahwa semakin tinggi pendidikan seseorang maka akan semakin mudah orang tersebut menerima informasi dan semakin banyak pengetahuan yang dimiliki seseorang maka akan semakin meningkatkan kinerjanya. Dengan demikian, tingkat pendidikan seseorang yang rendah akan dapat menghambat perkembangan sikapnya terhadap penerimaan, informasi, dan nilai-nilai yang baru diperkenalkan.

Tabel 4.2 Tingkat Pengetahuan Siswa-Siswi SMPN 77 dan SMAN 77

\begin{tabular}{lcccccc}
\hline \multirow{2}{*}{$\begin{array}{c}\text { Variabel } \\
\text { Pengetahuan }\end{array}$} & \multirow{2}{*}{ Kategori } & \multicolumn{2}{c}{ SMPN 77 } & \multicolumn{2}{c}{ SMAN 77 } \\
\cline { 4 - 7 } & & & $\begin{array}{c}\text { Pre- } \\
\text { Test }\end{array}$ & $\begin{array}{c}\text { Post- } \\
\text { Test }\end{array}$ & $\begin{array}{c}\text { Pre- } \\
\text { Test }\end{array}$ & $\begin{array}{c}\text { Post- } \\
\text { Test }\end{array}$ \\
\hline \multirow{2}{*}{ Perilaku Seksual } & $81--100$ & Tinggi & 22.41 & 40.77 & 25.93 & 49.12 \\
& $61--80$ & Sedang & 31.04 & 33.33 & 55.56 & 38.60 \\
Kesehatan Reproduksi & $0--60$ & Rendah & 46.55 & 25.93 & 18.52 & 12.28 \\
& $81--100$ & Tinggi & 1.72 & 14.82 & 18.52 & 35.09 \\
Seksual Pranikah dari & $81--80$ & Sedang & 68.97 & 74.07 & 61.11 & 63.16 \\
Sudut Agama & $0--60$ & Rendah & 29.31 & 11.11 & 20.37 & 1.75 \\
HukumPernikahan Dini & $81--100$ & Tinggi & 31.03 & 59.26 & 22.22 & 66.67 \\
& $61--80$ & Sedang & 39.66 & 29.63 & 50.00 & 24.56 \\
& $0--60$ & Rendah & 29.31 & 11.11 & 27.78 & 8.77 \\
& $61--80$ & Sedang & 34.48 & 40.74 & 25.93 & 19.30 \\
& $0--60$ & Rendah & 34.49 & 20.37 & 18.51 & 7.02 \\
\hline
\end{tabular}

Sumber : Data Primer diolah (2018) 
Pendidikan merupakan faktor penting yang dapat memengaruhi kemampuan kognitif seseorang. Tingkat pendidikan juga memengaruhi persepsi seseorang. Carter (2011) mengatakan bahwa semakin tinggi tingkat pendidikan seseorang maka ia akan semakin mudah menerima informasi dan memiliki penalaran yang tinggi pula. Penelitian yang dilakukan oleh Eberhardit et al. (2007) terhadap 74 responden yang berlatar pendidikan berbeda menunjukkan bahwa semakin tinggi level pendidikan responden maka tingkat pengetahuan yang dimiliki semakin luas dan kemampuan koqnitifnyajuga semakin tinggi.

Dalam kegiatan ini, nilai dan tingkat pengetahuan siswa-siswi SMPN 77 dan SMAN 77 ditingkatkan melalui metode ceramah dan diskusi untuk memberi bekal ilmu dalam upaya cegah seks pranikah (Gambar 1 ).
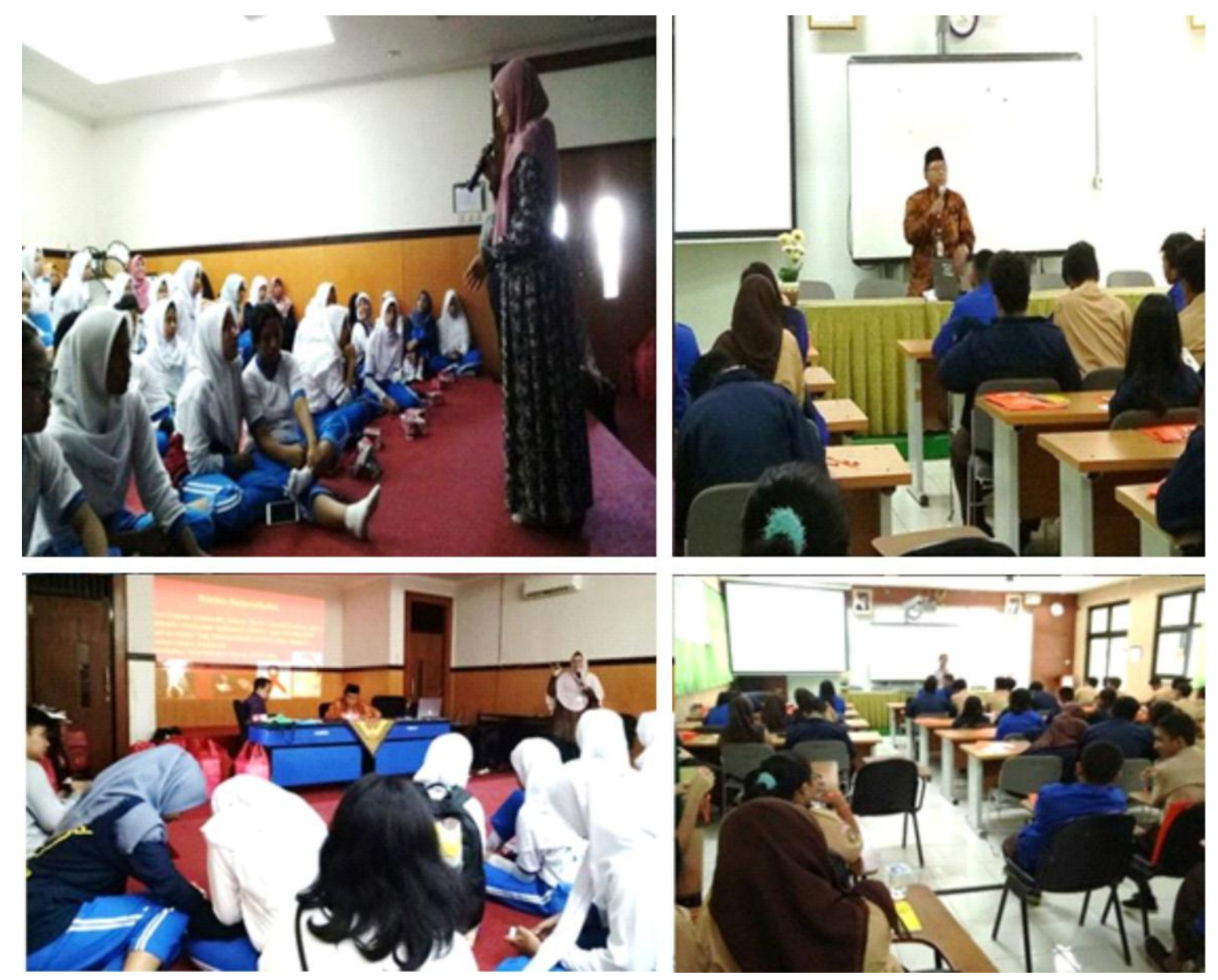

Sumber: Data Primer diolah (2018)

Gambar 1. Kegiatan Ceramah dan Diskusi dalam Upaya Cegah Seks Pranikahpada SiswaSiswi di SMPN 77 dan SMAN 77

Dari hasil analisis uji t berpasangan (Tabel 4.3) diketahui bahwa pengetahuan tentang perilaku seks, kesehatan reproduksi, dan pengetahuan agama untuk cegah seks pranikah pada siswa-siswi SMPN 77 meningkat secara bermakna $(\mathrm{p}<0.05)$ setelah dilakukan penyuluhan. Adapun pada siswa-siswi SMAN 77, pengetahuan agama dan hukum pernikahan dini untuk cegah seks pranikah meningkat secara bermakna $(\mathrm{p}<0.05)$ setelah dilakukan penyuluhan. 
Tabel 4.3 Peningkatan Pengetahuan Siswa-Siswi SMPN 77 dan SMAN 77

\begin{tabular}{lcccc}
\hline \multirow{2}{*}{ Pengetahuan } & \multicolumn{4}{c}{ SMPN 77 } \\
\cline { 2 - 5 } & Pre-test & Post-test & Peningkatan & kemaknaan \\
\hline Kesehatan Reproduksi & 66.9 & 82.61 & 15.71 & $0.000^{*}$ \\
Perilaku Seksual Pra nikah & 72.76 & 82.96 & 10.2 & $0.004^{*}$ \\
Agama & 77.93 & 88.89 & 10.96 & $0.002^{*}$ \\
Hukum Pernikahan Dini & 70.69 & 77.31 & 6.62 & 0.316 \\
\hline & \multicolumn{5}{c}{ SMAN 77 } \\
\hline Pengetahuan & Pre-test & Post-test & Peningkatan & kemaknaan \\
\hline Kesehatan Reproduksi & 88.33 & 88.51 & 5.18 & 0.135 \\
Perilaku Seksual Pra nikah & 81.11 & 87.37 & 6.26 & 0.221 \\
Agama & 78.15 & 91.23 & 13.08 & $0.000^{*}$ \\
Hukum Pernikahan Dini & 83.79 & 91.23 & 7.44 & $0.039^{*}$ \\
\hline
\end{tabular}

Sumber : Data Primer diolah (2018)

Dari hasil analisis regresi diketahui bahwa pengetahuan tentang kesehatan reproduksi dan pengetahuan agama pada siswa-siswi SMPN 77 (nilai $\mathrm{p}<0.05$ ) memiliki hubungan yang linier. Hasil penelitian ini membuktikan bahwa pengetahuan kesehatan reproduksi dan pengetahuan agama dapat memengaruhi perilaku seksual siswa SMPN 77, yakni semakin tinggi pengetahuan kesehatan reproduksi siswa maka semakin tinggi pula perilaku cegah seks pranikah dan semakin tinggi pengetahuan siswa terhadap agama maka semakin tinggi pula perilaku cegah seks pranikah.Hasil ini juga sesuai dengan hasil penelitian Lilestina (2012) yang menunjukkan adanya pengaruh antara pengetahuan kesehatan reproduksi dengan perilaku seksual pranikah, yaitu semakin tinggi pengetahuan tentang kesehatan reproduksi seseorang maka semakin baik pula perilaku seksualnya.

Dari hasil uji regresi tentang pengetahuan agama dan pengetahuan hukum pernikahan dini pada siswa-siswi SMAN 77 diketahui bahwa terdapat hubungan linier $(\mathrm{p}<0.05)$. Hasil penelitian ini menjelaskan bahwa pengetahuan agama dan hukum pernikahan dini memengaruhi perilaku seksual, yakni semakin tinggi pengetahuan agama seseorang maka semakin tinggi pula perilaku cegah seks pranikah. Hasil ini juga sejalan dengan penelitian yang dilakukan Nisfadlhilahet al. (2008) yang menyatakan bahwa ada hubungan negatif yang sangat bermakna $(\mathrm{p}=0.007)$ antara religiositas dengan perilaku seksua lremaja yang sedang pacaran, yakni semakin tinggi pengetahuan agama si remaja maka perilaku seksualnya pun akan semakin rendah dan sebaliknya. Dengan demikian, pengetahuan agama berpengaruh terhadap perilaku seks pranikah remaja dan orang yang agamanya baik akan memiliki rasa takut untuk melakukan perbuatan yang bertentangan dan dilarang dalam agamanya (Andisti\&Ritandiyono, 2008).

Fondasi penting untuk mencegah remaja dari aktivitas seksual pranikah adalah agama. Sarwono (2011) menyatakan bahwa moral dan religi dapat mengendalikan tingkah laku remajasehingga tidak melakukan hal-hal yang merugikan atau bertentangan dengan pandangan masyarakat. Pemahaman agama yang berkelanjutan pada remaja dapat 
membentuk pribadi yang berperilaku positif dan mencegah perilaku negatif, seperti perilaku yang berisiko (Koenig, Smith \& Denton, Wagener dalam Laytonet al., 2011).

Salah satu penyebab rusaknya moral remaja dalam hal seksualitas adalah perkembangan dan kematangan seksual yang seringtidak diiringi dengan peningkatan pengetahuan agama sehingga kaum remaja dapat terlibat dalam pergaulan seks pranikah dan penyimpangan orientasi seksual. Oleh karena itu, perlu adanya penanaman dan peningkatan pengetahuan perilaku seks dan pendidikan agama yang dapat menjadi pengontrol kaum remaja. Agama merupakan salah satu sumber nilai moral atau norma perilaku yang penting bagi jiwa remaja. Tidak adanya moral agama sering kali memicu terjadinyakenakalan remaja.

Hukum di Indonesia mengatur pernikahan dalam Undang-Undang No.1 Tahun 1974 yang menyatakan bahwa pernikahan adalah ikatan lahir batin antara seorang pria dengan seorang wanita sebagai seorang suami istri dengan tujuan membentuk keluarga yang bahagia dan kekal berdasarkan Ketuhanan Yang Maha Esa. Adapun batas usia pernikahan dalam Undang-Undang Perkawinan Bab II Pasal 7 Ayat 1 adalah pihak pria telah mencapai umur 19 tahun dan pihak perempuan sudah mencapai umur 16 tahun. Pernikahan di bawah batas usia tersebut akan berdampak pada kesehatan reproduksi anak perempuan. Secara biologis, organorgan reproduksi anakperempuan yang baru menginjak akil balig masih berada pada prosesmenuju kematangan sehingga belum siap untuk melakukan hubungan seks dengan lawan jenisnya, apalagi hamildan melahirkan. Jika hal tersebut terjadi akan memunculkan trauma, perobekan yang luas, dan infeksiyang akan membahayakan organ reproduksi, bahkan sampai membahayakan jiwa anak.

Hasil analisis regresi menunjukan bahwa pengetahuan tentang pernikahan dini untuk cegah seks pranikah meningkat secara bermakna setelah penyuluhan. Hasil ini diharapkan akan dapat meningkatkan pemahaman para siswa tentang dampak pernikahan dini terhadap kesehatan reproduksi dan mencegah perilaku seks pranikah.Hubungan linieritas dari hasil studi ini memberi gambaran bahwa meningkatnya pengetahuan tentang kesehatan reproduksi, agama, dan hukum negara akan meningkatkan pengetahuan untuk mencegah perilaku seksual pranikah, khususnya pada siswa-siswi SMP dan SMA. Hasil studi ini mendukung hasil penelitian Astuti \& Sulkasno (2011), yakni semakin baik tingkat pengetahuan remaja tentang kesehatan reproduksi maka mereka semakin tidak akan melakukan penyimpangan perilaku seksual pranikah. Pratiwi\& Hari (2010) juga mendapatkan hubungan yangsignifikan antara tingkat pengetahuan tentang kesehatan reproduksi dengan perilaku seksual, yakni perilaku seksual berisiko terjadi lebih tinggi pada remaja dengan tingkat pengetahuan rendah dari pada remaja dengan tingkat pengetahuan menengah dan tinggi.

\section{SIMPULAN}

Kegiatan pengabdian berupa pembekalan melalui ceramah dan diskusi tentang materi perilaku seksual, kesehatan reproduksi, pemahaman agama, dan pemahaman hukum pernikahan dini dapat meningkatkan pengetahuan siswa-siswi SMPN dan SMAN 77 Jakarta Pusat dalam upaya mencegah perilaku seks pranikah.Kegiatan serupa perlu dilakukan untuk mencari faktor-faktor lain yang dapat dijadikan sebagai sarana mencegah seks pranikah dikalangan remaja. 


\section{DAFTAR PUSTAKA}

Andisti,M.A.,\&Ritandiyono.2008.Religiusitas dan perilaku seks bebas pada dewasa awal. Jurnal Psikologi, 1 (2), 170-176.

Astuti, D.\& Sukasno. 2011. Hubungan Pengetahuan Remaja tentang Kesehatan Reproduksi dengan Perilaku Seksual Kelas XI di SMAN Gebog Kudus. Jurnal Kepererawatan dan Kebidanan, 2(1), 59-76.

BKKBN. 2011. Profil Pendataan KeluargaTahun 2011. Jakarta : Badan Kependudukan dan Keluarga Berencana Nasional Direktorat Pelaporan dan Statistik.

Carter, W. 2011. Disaster Manegement: A DisasterManager'sHandbook. Manila: ADB.

Darmasih, R. 2011. Kajian Sex Pranikah Remaja SMA di Surakarta.Jurnal Kesehatan, 4(2), 111119.

Djamba, Y.K. 2013. Sexual Practices in Africa. A.K. Baumle (Ed.). International Handbook on The Demography of Sexuality Dordrecht. Springer.

Eberhardtet al. 2007. Long-term investigation of a deep-seated creeping land slide incrystalline rock. Part II .Mitigation measures andnumerical modelling of deep drain age at Campo Vallemaggia.Canadian Geotechnical Journal, 44(10), 8-12.

Laytonet al. (2011). Anchors of Religious Commitment in Adolescents. Journal of Adolescent Research, 26(3), 381-413. Sage Publication.

Lilestina, S. (2012). Pengaruh Pengetahuan tentang Kesehatan Reproduksi Remaja Terhadap Perilaku Seksual Pranikah Remaja di Indonesia. Widyariset, Vol. 15 No.1.

Nisfadhilah et al. 2008. Hubungan Tingkat Pengetahuan AgamaIslam dengan Sikap Perilaku Seks Bebas Remajadi Madrasah Aliyah NegeriIII Malang. Skripsi Universitas BrawijayaMalang.

Notoatmodjo, S. 2012.Metodologi Penelitian Kesehatan. Jakarta: Rineka Cipta.

Pratiwi, N.L. \&HariB. 2010.Analisis Hubungan Perilaku Seks Pertama Kali Tidak Aman pada RemajaUsia 15-24 Tahun dan Kesehatan Reproduksi. Buletin PenelitianSistemKesehatan, 13(4).

Sarwono, S.W. 2011. Psikologi Remaja.Jakarta: PT Raja Grafindo Persada.

Soetjiningsih. 2012. Perkembangan Anak dan Permasalahannya dalam Buku Ajar I Ilmu. Perkembangan Anak dan Remaja. Jakarta:Sagungseto.

Suryoputro, A. et al. 2006. Faktor-Faktor yang Mempengaruhi Perilaku Seksual Remaja di Jawa Tengah: Implikasinya Terhadap Kebijakan dan Layanan Kesehatan Seksual dan Reproduksi. Makara kesehatan, Vol. 10(1), 29-40. 